\title{
Effects of laser dimple texturing on the sliding wear of friction pairs
}

\author{
Jian Zhan and Mingjiang Yang \\ Institute of Mechanics, Chinese Academy of Sciences, Beijing 100190, China
}

(Received 21 January 2013; accepted for publication 21 May 2013; published 4 June 2013)

\begin{abstract}
In order to reduce the sliding wear of friction pairs under dry friction condition, the surfaces of friction pairs were textured with morphology of dimples using laser etching technique, and the influence of surface micromorphology on the wear rate of friction pairs was studied. The results show that the laser dimple texturing can reduce abrasive wear of the friction pairs when they were in rolling contact and sliding movements, the occurrence of pear-shaped ditches was eliminated and damage of the surface oxide layer was relieved. The well-preserved surface oxide layer would restrain the penetration of air oxygen molecules into the friction pair, thanks to the dense oxide layer, and thereby reduce the wear rate. For the friction pair textured with morphology of etched dimples, the oxide layer is well preserved, its wear rate is reduced, and the oxygen atomic mass percentage on the surface is rather low. (C) 2013 Laser Institute of America.
\end{abstract}

Key words: wear, rolling contact friction pair, oxide layer, laser dimple texturing

\section{INTRODUCTION}

The rolling contact of a wheel on a rail is the key to many wheel-rail related problems such as wear rate, plastic deformation, rolling contact fatigue, vehicle dynamics, and vehicle-track interaction. The wear rate of wheel surface during rolling and sliding is originated from creep movement between the wheel surface and the rail. The present paper focuses on the effect of laser dimple texturing on the improvement of the wheel's wear rate and its variation rules so as to promote the engineering applications of laser surface texturing technique to the manufacture of high speed trains.

Milan et al. ${ }^{1}$ found that an increase in test temperature and normal load facilitated the generation of oxide and assisted in the compaction of the debris, thus producing a wear protective layer and, as a consequence, a reduction in wear rate as well as in friction coefficient. Birol ${ }^{2}$ found that the friction and wear conditions were quite stable owing to a stable oxide layer. Wong et al. ${ }^{3}$ found that rolling cycles generated more oxide on the surface of the patches, and the presence of these patches provided a relatively low and stable friction. Stott ${ }^{4,5}$ employed some of the models developed to account for the generation of oxide during sliding and studied the effects of such oxides on the wear rate. And it was found that oxidation of the contacting metal or alloy surfaces could result in a decrease in wear rate, usually associated with a change from metallic debris to oxide debris. Jiang et al. ${ }^{6}$ researched the mechanisms of establishment of this layer and found that the relatively low wear rate in the mild wear regime could be accounted for by the formation of a compact layer of oxide or oxide debris particles. Huttunen-Saarivirta ${ }^{7}$ found that the oxide scales played a more important role as the temperature increased, particularly in the case of uncoated specimens. On coated specimens, the oxide scales were extremely thin, particularly at the lowest temperatures, and were able to deform plastically with the base metal: they played a minor role in the erosion process. Voisey et $\mathrm{al}^{8}{ }^{8}$ found that laser surface melting created a refined microstructure that increased the effective diffusion coefficient for $\mathrm{Cr}$ in the alloy by introducing a higher density of rapid diffusion paths and thus promoting the formation of a protective oxide scale. And the resistance of alloys to corrosion relies on the formation of a dense, adherent oxide layer that separates the alloy from the corrosive environment. The result of Joos et al. ${ }^{9}$ showed that for a disc of temperature below $650^{\circ} \mathrm{C}$, the decrease of the friction coefficient was essentially due to the disc oxide scale for both grades. And above $650^{\circ} \mathrm{C}$, the contribution of the pin oxide scale influenced the friction evolution. Rainforth et al. ${ }^{10}$ found that an increase in oxide coverage of the surface was associated with a decrease in Lancaster wear coefficient. The oxide at the surface of the $316 \mathrm{~L}$ and $\mathrm{H} 21+7 \% \mathrm{TiC}$ was found to deform with the substrate, forming a mechanically mixed layer that enhanced the surface wear resistance.

In previous studies, since surface morphology of the rolling contact friction pair was uncontrollable and the formation of oxide layers in friction was stochastic, it is very difficult to study the variation rules governing the wear rate of friction pairs. In the present paper, the formation of surface oxide layer is affected and controlled by changing the morphology of the laser-textured surface of friction pairs so

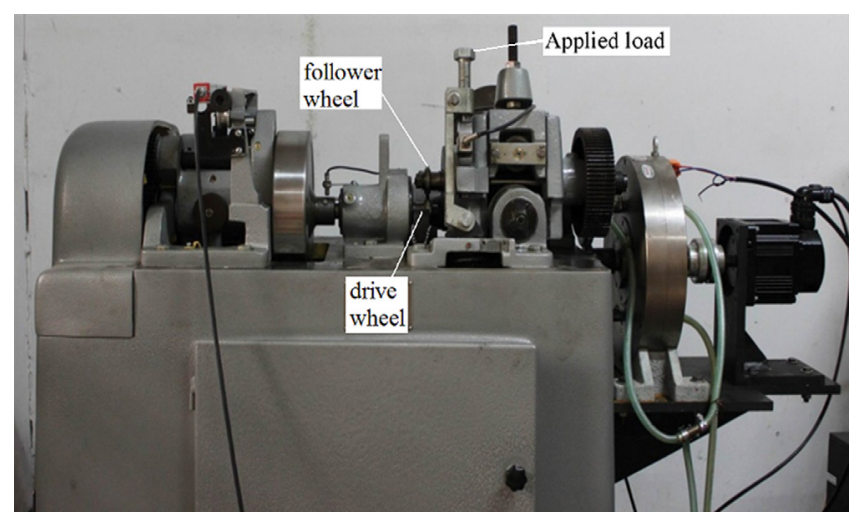

FIG. 1. The testing rig. 
TABLE I. The chemical components and mechanical performances of the materials.

\begin{tabular}{ccccccccccc}
\hline \hline Steel & $\omega(\mathrm{C})(\%)$ & $\omega(\mathrm{Si})(\%)$ & $\omega(\mathrm{Mn})(\%)$ & $\omega(\mathrm{Ni})(\%)$ & $\omega(\mathrm{Cr})(\%)$ & $\omega(\mathrm{S})(\%)$ & $\omega(\mathrm{P})(\%)$ & $\sigma_{\mathrm{s}}(\mathrm{MPa})$ & $\sigma_{\mathrm{b}}(\mathrm{MPa})$ & $\mathrm{HRC}$ \\
\hline $45 \mathrm{C}$ & 0.45 & 0.27 & 0.65 & 0.25 & 0.25 & $\leq 0.02$ & $\leq 0.02$ & 600 & 800 & 26 \\
\hline \hline
\end{tabular}

that the effects of surface oxide layer on the wear rate of friction pairs can be studied in detail. The results of Seo ${ }^{11}$ show that when the dimple diameter in the wear area is less than certain threshold, this dimple has little influence on the wear situation nearby, and the dimple will gradually fade away under the action of wearing; while as the dimple diameter surpasses the threshold, fissures and lots of debris will be found around the dimple due to the action of wearing. The result proves that the laser dimple texturing on the surface of friction pairs would not affect the friction pairs themselves, i.e., the laser texturing technique is feasible.

\section{EXPERIMENTAL PROCEDURE}

Wear between the wheel surface and the rail is a rolling and sliding (creep) wear. The key for reducing the wear rate is to accelerate the formation of an oxide layer on the friction pair surface and to delay the damage of this oxide layer.

The experiment was carried out on a rolling friction testing rig, as shown in Fig. 1, in which the rolling and sliding are generated by applying a load of eddy resistance to the follower wheel. The base material of the follower wheel is Steel 45C, and its chemical components are given in Table I. The material of the drive wheel is Steel 45C after quenching heat treatment, the HRC of which is 52. The follower wheels were divided into three groups: the first were those without laser treatment, the second those treated by laser dimple texturing with etched dimples, as shown in Fig. 2(a), and the third those treated by laser dimple texturing, in which the dimple has melted crater, as shown in Fig. 2(b); the experimental results would also be grouped into three cases in the following presentation. In this test, the dimples were produced in air without special environmental requirement by a $5 \mathrm{kHz}$ pulsating $\mathrm{Nd}$ :YAG laser with power of $200 \mathrm{~W}$, focus length of $80 \mathrm{~mm}$, and pulses of $5 \mu \mathrm{s} \mathrm{du}-$ ration, and $10 \mathrm{~mJ}$ for each pulse. In the experiment, one dimple was produced by two repeat laser pulses, and the laser peak power density was $3.74 \times 10^{7} \mathrm{~W} / \mathrm{cm}^{2}$ for case 2 [Fig. 2(a)] and $3.14 \times 10^{7} \mathrm{~W} / \mathrm{cm}^{2}$ for case 3 [Fig. 2(b)], respectively. The drive wheel is $45.4 \mathrm{~mm}$ in diameter and $5 \mathrm{~mm}$ in width, and the follower wheel is $45.4 \mathrm{~mm}$ in diameter and $10 \mathrm{~mm}$ in width. And then comparative experiments were performed, the laser beam is $140 \mu \mathrm{m} \times 140 \mu \mathrm{m}$ in focus size and the diameter of laser etched dimple is $100 \mu \mathrm{m}$ (for dimples with crater, the diameter is measured from the crater's border), and the dimple depth is $30 \mu \mathrm{m}$ (the same for dimples with crater, whereas the height of the crater is about $8 \mu \mathrm{m})$. In experiments, the rotating speed is $400 \mathrm{r} / \mathrm{min}$, the treatment duration is $26 \mathrm{~h}$, and the load is $500 \mathrm{~N}$. Each experimental run had a grinding-in duration of $5 \mathrm{~min}$ and then a resistant load was applied on the follower wheel, in which the eddy current was $0.75 \mathrm{~A}$ and the friction coefficient of the friction pair was steady and kept at 0.17 .

\section{RESULTS}

Figure 3 showed that the surface morphology of the follower wheels with laser treatment: the laser dimple texturing with etched dimples, as shown in Fig. 3(a), and the laser dimple texturing with melted crater, as shown in Fig. 3(b). Figure 4(a) shows the results for case 1, i.e., morphology of the untreated friction pair after the wearing test, in which interrupted pear-shaped ditches could be clearly seen in wear area. These interrupted pear-shaped ditches were caused by the rolling and sliding movements of debris particles that were generated during the wearing test. These debris particles damaged and prolonged the formation of oxide layer on the friction pair surface so that the wear state became deteriorated. The thickness of the oxide layer was approximately $10 \mu \mathrm{m}$, as seen in Stott. ${ }^{5}$ On the other hand, for case 2 , i.e., for the treated friction pair of the second group (laser texturing with etched dimples), the wear situation after the wearing test was shown in Fig. 4(b), in which the interrupted pear-shaped ditches were not observed. This is because the dimples blocked the sliding movements of debris particles on the friction pair surface, leading to quick formation of oxide layer on the friction pair surface. The oxide layer was not liable to be damaged by debris particles, and thereby the wear rate was significantly reduced. For case 3 [where the

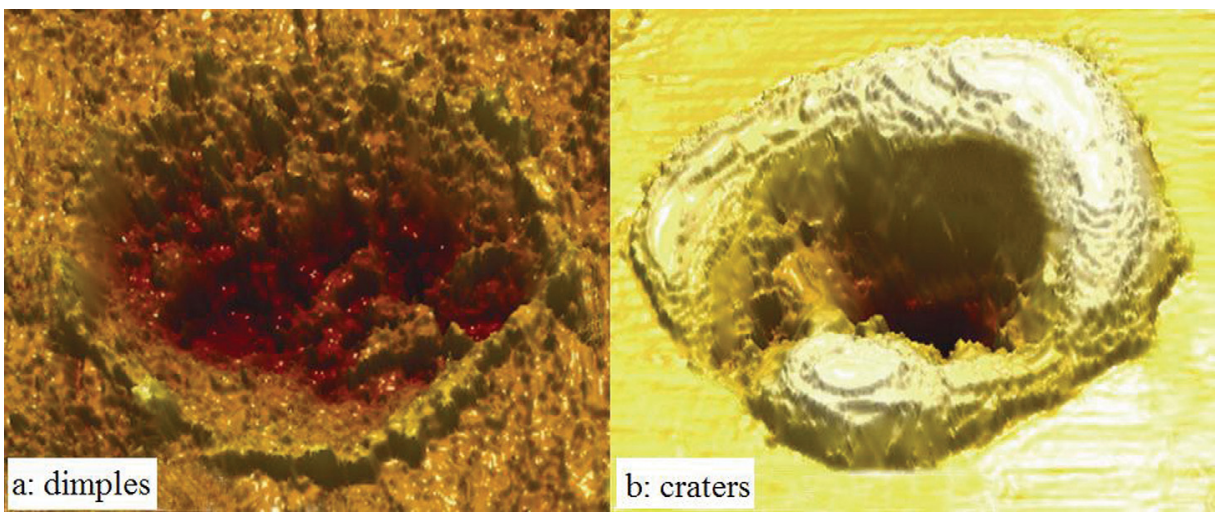

FIG. 2. Magnification of the dimples. 


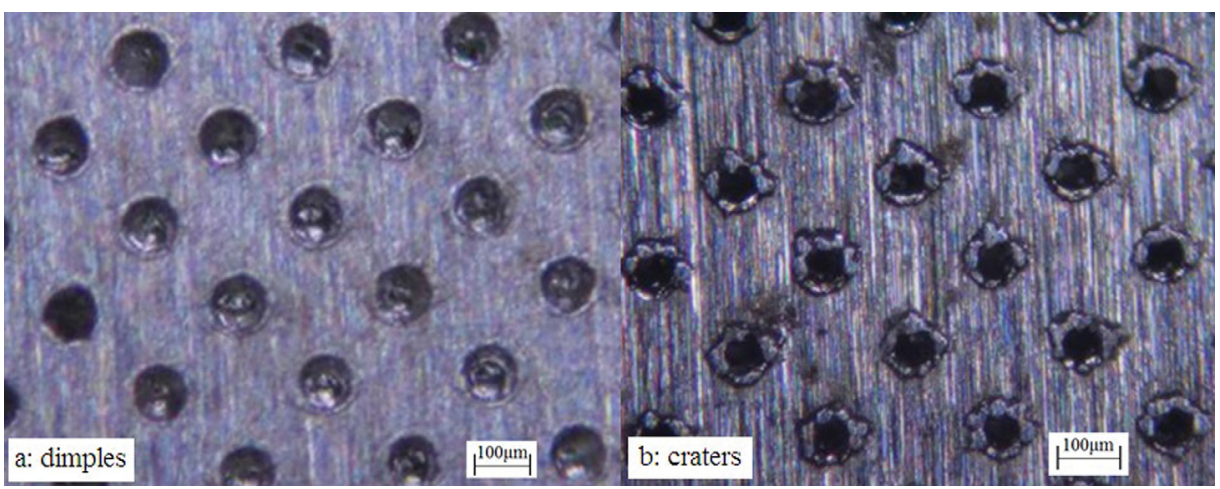

FIG. 3. Morphology of the dimples.

laser-textured surface changed from morphology of etched dimples to morphology of dimples with craters, as shown in Fig. 2(b)], since the crates on the surface of the follower wheel generated lots of debris particles on the drive wheel surface in the sliding movements, thus the oxide layer took the longest time to form and was difficult to be preserved and soon be damaged by debris particles. The pear-shaped ditches formed regular connected grooves on the drive wheel surface, and furthermore, the movements of these debris particles also generated lots of grooves on the surface of the follower wheel, as shown in Fig. 4(c), so that the wear rate of the friction pair was greatly elevated.
Abrasion loss of the friction pair is compared in Table II. For case 2 (where the follower wheel is laser-textured with morphology of etched dimples), the reduction in abrasion loss of the follower wheel is $(16.8-5.4) / 16.8=67.8 \%$, and that of the drive wheel is $(7.9-0.7) / 7.9=91.1 \%$. For case 3 (where the follower wheel is laser-textured with morphology of dimples with craters), the increment in abrasion loss of the follower wheel is $(25.1-16.8) / 16.8=49.4 \%$ and that of the drive wheel is $(39.0-7.9) / 7.9=390 \%$. The oxygen atomic mass percentage on the worn surface with no laser treatment was $5.88 \%$ from the energy spectrum analysis, the oxygen atomic mass percentage on the worn surface
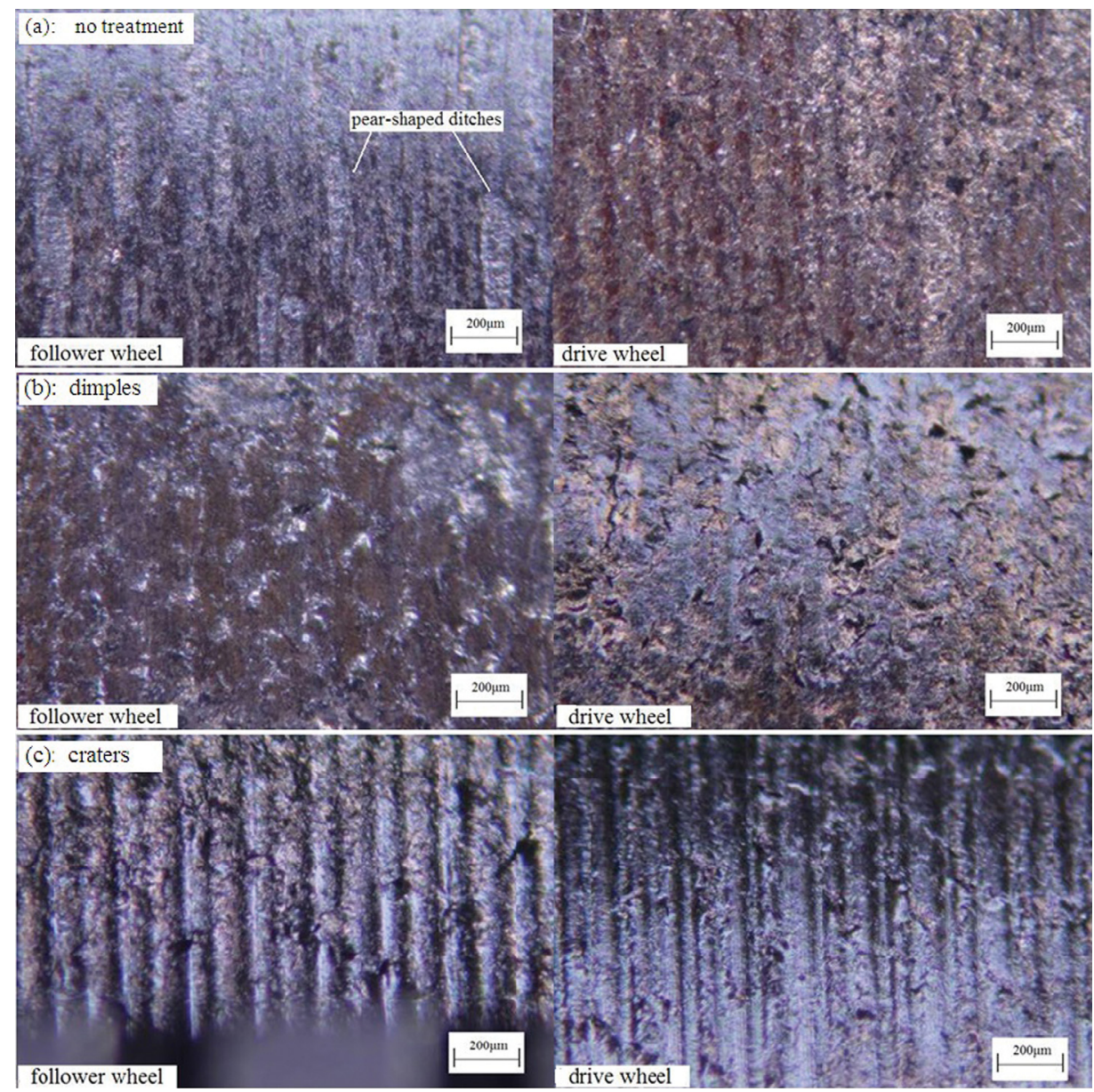

FIG. 4. Wear situation [(a) no treatment; (b) dimples; and (c): craters]. 
TABLE II. Effects of laser texturing on the abrasion loss of friction pairs in rolling and sliding.

\begin{tabular}{lcccc}
\hline \hline & Laser treated follower wheel & $\begin{array}{c}\text { Abrasion loss of the } \\
\text { follower wheel (mg) }\end{array}$ & $\begin{array}{c}\text { Abrasion loss of the } \\
\text { drive wheel (mg) }\end{array}$ & $\begin{array}{c}\text { Oxygen atomic mass } \\
\text { percentage (\%) }\end{array}$ \\
\hline \multirow{3}{*}{ Laser texturing } & Without laser treatment & 16.8 & 7.9 & 5.88 \\
& Morphology of etched dimples & 5.4 & 0.7 & 3.72 \\
& Morphology of dimples with craters & 25.1 & 39.0 & 6.96 \\
\hline \hline
\end{tabular}

with dimples was $4.72 \%$, and the oxygen atomic mass percentage on the worn surface with craters was $6.96 \%$, as in Table II.

\section{DISCUSSION}

After wearing tests, the colors of the three friction pairs were eye-observed, the untreated pair exhibits sandy beige color, the friction pair textured with etched dimples is dark brown, while the friction pair textured with dimple with crater is grey white.

Figure 5(a) shows the oxide layer on the surface of the untreated drive wheel together with its energy spectrum. The oxide layer was fragmentary, and the oxygen atomic mass percentage on the worn surface was $5.88 \%$ from the energy spectrum analysis. Figure 5(b) shows the oxide layer on the surface of the drive wheel for case 2 (where the follower wheel was textured with morphology of etched dimples) and its energy spectrum. The oxide layer was quite intact, and no obvious fragments were observed. The oxygen atomic mass percentage on the worn surface was $4.72 \%$ from corresponding energy spectrum analysis. Figure 5(c) shows the oxide layer on the drive wheel surface for case 3 (where the follower wheel was textured with morphology of dimples with craters) together with its energy spectrum. The oxide layer was seriously worn off with obvious stripping, and the oxygen atomic mass percentage on the worn surface was $6.96 \%$ from corresponding energy spectrum analysis.

For the oxide layer on the friction pair surface, the high to low rank of the intactness is case 2 (the laser-textured surface with morphology of etched dimples) — case 1 (the untreated surface) — case 3 (the laser-textured surface with morphology of dimples with craters). The high to low rank of the oxygen atomic mass percentage on the worn off surface is case 3 (the laser-textured surface with morphology of dimples with craters)—case 1 (the untreated surface)—case 2 (the lasertextured surface with morphology of etched dimples).
The intactness of the oxide layer on the friction pair surface reflects the degree of difficulty for oxygen molecules to penetrate into the surface. The denser the oxide layer on the friction pair surface, the less liable for the oxide layer to fracture, the longer the oxide layer lasts, the stronger the capability of the friction pair to resist further oxidation, and the lower the oxygen atomic mass percentage in the energy spectrum analysis. In this case, the oxide layer can effectively prevent the friction pair from further wear and tear, leading to the reduction of wear rate of the friction pair. Otherwise, if the oxide layer is liable to be damaged in movements, as shown in Fig. 4(a), even peeled off in case of severe wear, as shown in Fig. 4(c), then air oxygen molecules are easy to penetrate into the surface, leading to enhanced oxygen atomic mass percentage on the surface. In this case, the oxide layer cannot effectively prevent the friction pair from wear and tear. It can thus be concluded that the laser dimple texturing can reduce the wearing action of debris particles on the friction pair during rolling and sliding, delay the damage of the surface oxide layer, and reduce the wear rate.

\section{CONCLUSIONS}

The influence of surface micromorphology on the wear rate of friction pairs was studied in the present paper and the following conclusions are drawn.

Surface oxide layer plays the role of restraining wear and tear in rolling-sliding movements. The intactness of the surface oxide layer in movements can be controlled via the control of the micromorphology of friction pair surfaces. When the surface oxide layer is well preserved, the oxygen atomic mass percentage on the surface is rather low, which restrains the penetration of air oxygen molecules into the surface. For laser dimple textured friction pairs, the surface oxide layer is well preserved and thus the wear rate is rather low.
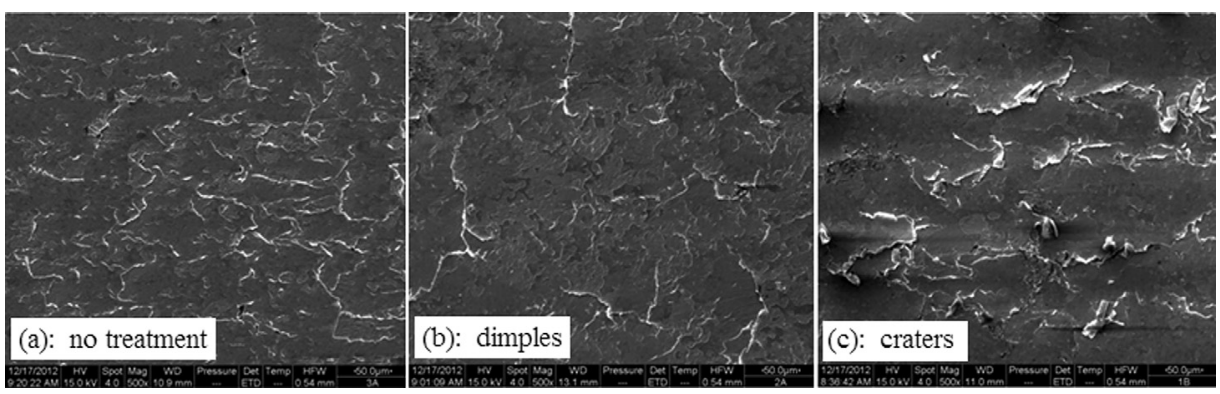

FIG. 5. Oxide layer on the drive wheel surface [(a) no treatment; and (b) dimples; and (c) craters]. 
${ }^{1}$ J. C. G. Milan, M. A. Carvalho, R. R. Xavier, S. D. Franco, and J. D. B. De Mello, "Effect of temperature, normal load and pre-oxidation on the sliding wear of multi-component ferrous alloys," Wear 259, 412-423 (2005).

${ }^{2}$ Y. Birol, "High temperature sliding wear behaviour of Inconel 617 and Stellite 6 alloys," Wear 269, 664-671 (2010).

${ }^{3}$ K. C. Wong, X. Lu, J. Cotter, D. T. Eadie, P. C. Wong, and K. A. R. Mitchell, "Surface and friction characterization of $\mathrm{MoS}_{2}$ and $\mathrm{WS}_{2}$ third body thin films under simulated wheel-rail rolling-sliding contact," Wear 264, 526-534 (2008).

${ }^{4}$ F. H. Stott, "The role of oxidation in the wear of alloys," Tribol. Int. 31(1-3), 61-71 (1978).

${ }^{5}$ F. H. Scott and G. C. Wood, "The influence of oxides on the friction and wear of alloys,” Tribol. Int. 11(4), 211-215 (1998).

${ }^{6}$ J. Jiang, F. H. Stott, and M. M. Stack, "A mathematical model for sliding wear of metals at elevated temperatures," Wear 181-183(Part 1) 20-31 (1995).
${ }^{7}$ E. Huttunen-Saarivirta, S. Kalidakis, F. H. Stott, V. Rohr, and M. Schütze, "Erosion-oxidation of uncoated, aluminized and chromized-aluminized $9 \mathrm{Cr}-1 \mathrm{Mo}$ steels under fluidized-bed conditions at $550-700^{\circ} \mathrm{C}$," Tribol. Int. 43(1-2), 161-170 (2010).

${ }^{8}$ K. T. Voisey, Z. Liu, and F. H. Stott, "Inhibition of metal dusting of Alloy $800 \mathrm{H}$ by laser surface melting," Appl. Surf. Sci. 252(10), 3658-3666 (2006).

${ }^{9}$ O. Joos, C. Boher, and C. Vergne, "Assessment of oxide scales influence on wear damage of HSM work rolls," Wear 263(1-6), 198-206 (2007).

${ }^{10}$ W. M. Rainforth, A. J. Leonard, C. Perrin, A. Bedolla-Jacuinde, Y. Wang, H. Jones, and Q. Luo, "High resolution observation of friction-induced oxide and its interaction with the worn surface," Tribol. Int. 35, 713-748 (2002).

${ }^{11}$ J. Seo, S. Kwon, and D. Lee, "Effects of surface defects on rolling contact fatigue of rail,” Procedia Eng. 10, 1274-1278 (2011). 